\title{
Gesundheitsausgaben
}

\section{Stabilitätsfaktor für die Wirtschaft}

\author{
Kostenfaktor oder Wachstumstreiber? Darüber lässt sich bei den \\ Gesundheitsausgaben trefflich streiten. Anlass dazu boten vor \\ Kurzem Zahlen des Statistischen Bundesamts.
}

m April informierte das Statistische Bundesamt über die Entwicklung der Gesundheitsausgaben in Deutschland im Jahr 2010. Sie waren gegenüber dem Vorjahr um 3,2\% gestiegen. Doch der Anteil der Gesundheitsausgaben am Bruttoinlandsprodukt war gleichzeitig von $11,7 \%$ auf $11,6 \%$ gesunken. Der interessierte Bürger staunt - was ist geschehen?

Die Statistiker des Bundesamtes lieferten die Erklärung gleich mit: Der leichte Rückgang dieses Indikators sei auf den starken Anstieg des Bruttoinlandsprodukt nach dem Krisenjahr 2009 zurückzuführen. Der Zuwachs der Gesundheitsausgaben im Jahr 2010 entspreche tatsächlich in etwa dem durchschnittlichen jährlichen Wachstum zwischen 2000 und 2009, das bei 3,0\% lag. Doch halt - brauchen wir dann also den Anteil der Gesundheitsausgaben am Bruttoinlandsprodukt gar nicht, wenn er ja nichts über die Entwicklung der Gesundheitsausgaben aussagt?

\section{Antizyklische Entwicklung}

Das Gegenteil ist richtig: Gerade die Tatsache, dass sich der Anteil der Gesundheitsausgaben an der gesamten Wirtschaftsleistung (dem Bruttoinlandsprodukt) leicht von $11,7 \%$ auf $11,6 \%$ vermindert hat, obwohl die Gesundheitsausgaben absolut um 8,9 Milliarden Euro auf nunmehr 287,3 Milliarden Euro gegenüber 2009 angestiegen waren, macht eine der Kernaussagen dieses Indikators deutlich. Hier geht es darum, welchen Anteil an der Wirtschaftsleistung einer Periode - im Allgemeinen also eines Jahres - eine Gesellschaft für die Gesundheit aufgewendet hat. Ist der Anteil gesunken, obwohl die Ausgaben absolut gestiegen sind, hat die Gesellschaft die Ausgaben für andere Bereiche stärker gesteigert als für die Gesundheit.

Die Entwicklung dieses Indikators ist deshalb für Fachleute auch keine echte Überraschung. Die Gesundheitsbranche insgesamt ist in ihrer Entwicklung antizyklisch. Geht es der Wirtschaft schlechter, stagniert also das Bruttoinlandsprodukt oder sinkt es sogar, wirkt sich dies nicht direkt auf die Gesundheitsbranche aus. Im Gegenteil, sie stabilisiert mit ihren weiter leicht wachsenden Ausgaben sogar die Gesamtwirtschaft und vor allem die Beschäftigung.

\section{Keine Alarmzeichen}

Folgerichtig muss sich der Anteil der Gesundheitsausgaben am Bruttoinlandsprodukt in einer solchen Phase erhöhen. Erholt sich die Wirtschaft dann wieder und wächst schneller, wirkt sich auch dies nicht unmittelbar auf die Ausgabenentwicklung in der Gesundheitsbranche aus - ihr Anteil am Bruttoinlandsprodukt stagniert oder sinkt leicht.

Drei Lehren können daraus gezogen werden. Erstens: Steigende absolute Gesundheitsausgaben allein sind weder gut noch schlecht! Zweitens: Sie stabilisieren in der Rezession sowohl die Gesamtwirtschaft als auch den Arbeitsmarkt. Drittens: Steigende oder sinkende Anteile der Gesundheitsausgaben an der Wirtschaftsleistung allein sind keine Alarmzeichen - erst der Blick auf die wirtschaftliche Entwicklung insgesamt macht sie interpretationsfähig.

Dr. Uwe K. Preusker

\section{4.}

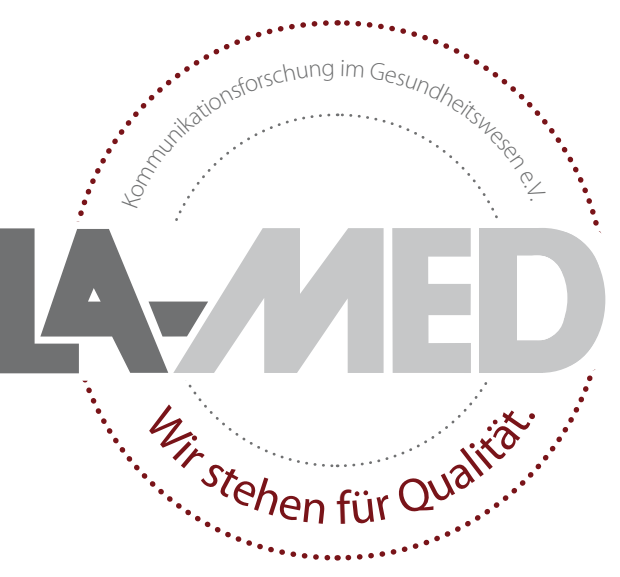

Sie lesen
Qualität

Damit das auch so bleibt, befragen wir Sie in Kooperation mit tns infratesı in den nächsten Wochen.

\section{Ihr Urteil ist uns wichtig.} Bitte nehmen Sie teil! 